\title{
Extended-Spectrum $\beta$-Lactam Resistant Klebsiella pneumoniae and Escherichia coli in Wild European Hedgehogs (Erinaceus europeus) Living in Populated Areas
}

\author{
Biel Garcias ${ }^{1}$, Laia Aguirre ${ }^{1}$ (D), Chiara Seminati ${ }^{1}$, Nerea Reyes ${ }^{1}$, Alberto Allepuz ${ }^{1,2}$ (D), Elena Obón ${ }^{3}$, \\ Rafael A. Molina-Lopez ${ }^{3}$ and Laila Darwich ${ }^{1,2, *(D)}$
}

1 Departament de Sanitat i Anatomia Animal, Universitat Autònoma de Barcelona (UAB), 08193 Cerdanyola del Vallès, Spain; biel.garcias@uab.cat (B.G.); Laia.aguirre@uab.cat (L.A.); Chiara.seminati@uab.cat (C.S.); Nerea.reyes@sanikolas.org (N.R.); Alberto.allepuz@uab.cat (A.A.)

2 IRTA, Centre de Recerca en Sanitat Animal (CReSA, IRTA-UAB), Campus de la Universitat Autònoma de Barcelona, 08193 Cerdanyola del Vallès, Spain

3 Catalan Wildlife Service, Centre de Fauna Salvatge de Torreferrussa, 08130 Santa Perpètua de Mogoda, Spain; Elena.obon@gencat.cat (E.O.); Rafael.molina@gencat.cat (R.A.M.-L.)

* Correspondence: Laila.darwich@uab.cat; Tel.: +34-935811046

check for updates

Citation: Garcias, B.; Aguirre, L.; Seminati, C.; Reyes, N.; Allepuz, A.; Obón, E.; Molina-Lopez, R.A.; Darwich, L. Extended-Spectrum $\beta$-Lactam Resistant Klebsiella pneumoniae and Escherichia coli in Wild European Hedgehogs (Erinaceus europeus) Living in Populated Areas. Animals 2021, 11, 2837. https:// doi.org/10.3390/ani11102837

Academic Editors: Anna Rita Attili, Alessandro Bellato, Patrizia Nebbia and Patrizia Robino

Received: 8 September 2021 Accepted: 23 September 2021 Published: 28 September 2021

Publisher's Note: MDPI stays neutral with regard to jurisdictional claims in published maps and institutional affiliations.

Copyright: (c) 2021 by the authors. Licensee MDPI, Basel, Switzerland. This article is an open access article distributed under the terms and conditions of the Creative Commons Attribution (CC BY) license (https:// creativecommons.org/licenses/by/ $4.0 /)$.
Simple Summary: The alarming emergence of antimicrobial resistance (AMR) in human and veterinary medicine has activated awareness for monitoring the levels of AMR pollution in the environment and wildlife. European hedgehogs (Erinaceus europaeus) are common wild species habiting urban areas in Europe. In this study, the occurrence and distribution of extended-spectrum $\beta$-lactam (ESBL) resistant enterobacteria and AMR genes were assessed in wild European hedgehogs in Catalonia, NE Spain. The results showed that $36.8 \%$ of the animals were detected as carriers of $\beta$ lactamase/carbapenemase resistance genes, with a special occurrence of human nosocomial bacteria such as Klebsiella pneumoniae, Escherichia coli, and Citrobacter freundii. In addition, more than half of the enterobacteria presented a multidrug resistance (MDR) phenotype and 31\% of the isolates had an extended XDR profile. No differences in the spatial distribution of animals with AMR genes were observed within the study region. The results of this study suggest that the close contact with human areas predispose the transmission of AMR genes to wild hedgehogs because they either inhabit and/or feed in an anthropogenic environment. In conclusion, hedgehogs could be good sentinels or bioindicators of AMR environmental pollution, especially in highly populated areas with high human activity.

Abstract: Wildlife has been suggested to be a good sentinel of environmental health because of its close interaction with human populations, domestic animals, and natural ecosystems. The alarming emergence of antimicrobial resistance (AMR) in human and veterinary medicine has activated/triggered the awareness of monitoring the levels of AMR pollution in wildlife. European hedgehogs (Erinaceus europaeus) are common wild species habiting urban areas in Europe. However, there are few studies conducted in hedgehogs as reservoirs of AMR bacteria or genes. The aim of this study was to assess the occurrence and distribution of ESBL, AmpC, and carbapenem-resistant enterobacteria and AMR genes in wild European hedgehogs in Catalonia, a densely populated region of NE Spain. A total of 115 hedgehogs admitted at the Wildlife Rehabilitation Center of Torreferrussa were studied. To our knowledge, this is the first description of $\beta$-lactam resistant enterobacteria in wild hedgehogs. Interestingly, 36.8\% (42/114) of the animals were detected as carriers of $\beta$-lactamase/carbapenemase resistance genes. Klebsiella spp. (59.6\%), and specifically K. pneumoniae $(84.6 \%)$, were the bacteria with the highest proportion of resistance genes, followed by E. coli (34.6\%) and C. freundii (5.8\%). The most frequently detected genetic variants were blaCTX-M-15 (19.3\%), blaSHV-28 (10.5\%), blaCMY-1 (9.7\%), blaCMY-2 (8.8\%), and blaOXA-48 (1.7\%). In addition, $52 \%(27 / 52)$ of the isolates presented a multidrug resistance (MDR) phenotype and $31 \%$ had an extended drug resistance (XDR) profile. No clustering of animals with AMR genes within the study region was shown in the spatial analysis, nor differences in the proportion of positive animals among 
regions, were detected. The results of this study suggest that wild European hedgehogs could be good sentinels of AMR environmental pollution, especially in areas with a high human population density, because they either inhabit and/or feed in an anthropogenic environment. In conclusion, it is crucial to raise awareness of the strong interconnection between habitats and compartments, and therefore this implies that AMR issues must be tackled under the One Health approach.

Keywords: wild European hedgehogs; antimicrobial resistance; ESBL; K. pneumoniae; E. coli

\section{Introduction}

Antimicrobial resistance (AMR) is a problem in human and veterinary medicine worldwide. The increasing prevalence of AMR in clinically important and commensal bacteria in both humans and livestock is attributed largely to selection through the use of antimicrobials [1,2]. However, the emergence of genes conferring resistance to human last-resort antibiotics, such as extended-spectrum $\beta$-lactamases (ESBLs), AmpC-type $\beta$ lactamases (AmpC), and carbapenem resistance genes, has been reported in the commensal bacteria of wildlife without any history of antimicrobial intake [3,4]. In fact, wild animals do not naturally come into contact with antimicrobials, but commensal bacteria have the potential to act as reservoirs of resistance genes contributing to the development of AMR in pathogens through horizontal transmission [3,5]. Thus, wildlife may be infected with antimicrobial-resistant bacteria (AMRB) or acquire AMR genes from human sources, agricultural facilities, and associated contaminated environments [6,7].

The European hedgehog (Erinaceus europaeus) is a common and widely distributed wild species in Europe. Hedgehogs are small, nocturnal, spiny-coated insectivores that live in a variety of habitats, generally in close contact with humans, but also with livestock in the countryside [8]. In recent years, hedgehog populations are increasingly inhabiting areas with human activity, such as gardens in residential areas or green areas in big cities [9]. Some of the consequences of this close hedgehog-human interaction is that people usually feed these animals and thus increases the risk of human physical contact. Moreover, the presence of hedgehogs in other anthropogenic environments, such as farms or crop fields, also allow for contact with livestock.

The prevalence of resistant bacteria in wildlife is linked with human activity [6]. Only a few studies have been conducted in hedgehogs reporting the presence of zoonotic antimicrobial resistant bacteria or AMR genes, such as $\beta$-lactam resistant Enterobacteriaceae in NE Spain [10], tetracycline resistance genes [11], or methicillin-resistant Staphylococcus aureus carrying mecC in Denmark and Sweden [12,13]. However, there is no research on the role of hedgehogs in AMRB dynamics at the interface between human populations, domestic animals, and natural ecosystems. This information is critical for implementing strategies to prevent further development and spread of AMRB between animals and humans.

Catalonia (NE Spain) is a densely populated county with a high density of pig fattening farms. Barcelona is Catalonia's capital, one of Europe's most densely populated cities. It is estimated that more than five million people live in the metropolitan area of Barcelona and the adjacent suburban areas, which is the largest on the Mediterranean Sea (Figure 1). Thus, the pressure on urban land on the main metropolitan areas of Barcelona is very high. As hedgehogs are a species closely related with the urban life, they could serve as reservoirs, vectors, and bioindicators of resistant bacterial pathogens and genetic determinants of AMR in the environment $[6,7,14]$. Therefore, the aim of this study was to assess the occurrence and distribution of ESBL, AmpC, and carbapenem-resistant enterobacteria in a wild population of European hedgehogs in Catalonia, NE Spain. 


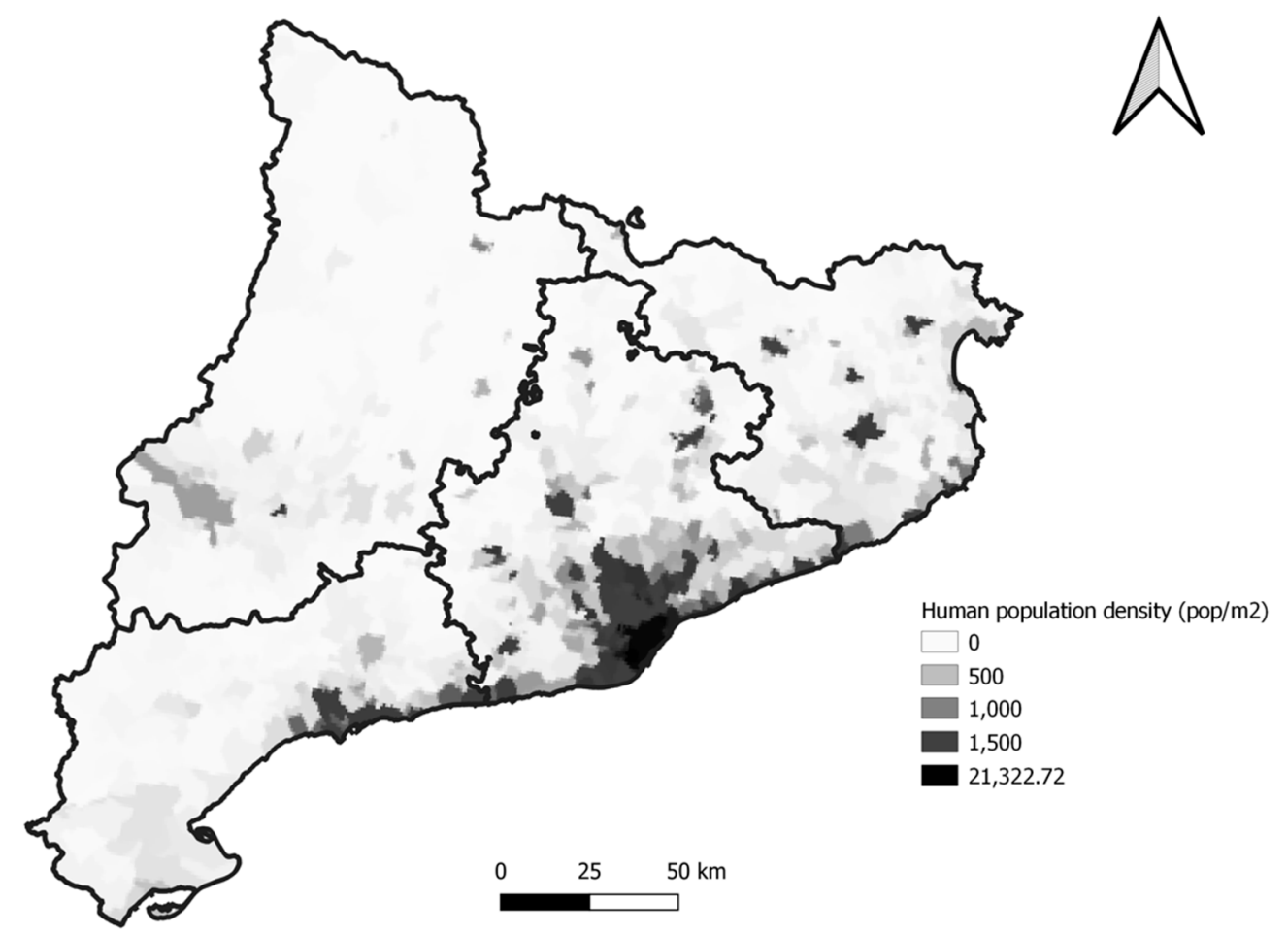

Figure 1. The map shows the human population density of Catalonia. Sampled animals were concentrated in the zones with a higher density.

\section{Materials and Methods}

\subsection{Study Population}

From 2015 to 2019, faeces from 114 hedgehogs were collected at the Wildlife Rehabilitation Center (WRC) of Torreferrussa (Catalunya, North-East Iberian Peninsula). Sampling methods and animal handling techniques were in agreement with the Catalan Wildlife Service, which specifies the management protocols and the Ethical Principles according to Spanish legislation [15].

Upon admission, a physical exam under inhalant anaesthesia with isofluorane was performed on the animals and rectal samples were collected using sterile swabs with an Amies transport medium (Deltalab, Barcelona, Spain), before any pharmacologic or antimicrobial treatment. Data of the origin of the hedgehogs were provided by the wildlife rangers who brought the animals to the WRC. The age and sex of the animals were recorded by veterinary staff of the WRC. The cause of admission was related to the following categories [16]: orphaned young $(27 \%)$, fortuitous finds $(27 \%)$, metabolic/nutritional disease $(15 \%)$, traumatic injuries $(14 \%)$, natural disease/incident $(13 \%)$, and other casualties such as illegal captivity or traps $(4 \%)$.

\subsection{Microbiological Analysis}

Rectal swabs were transported on an Amies medium to the Veterinary Infectious Diseases Diagnostic Laboratory located at the Autonomous University of Barcelona, Spain. Upon arrival, samples were processed immediately or were stored at $4{ }^{\circ} \mathrm{C}$ until being processed the next day. All rectal swabs were directly cultured on Columbia blood agar (BD GmBh, Munich, Germany) and MacConkey agar (Oxoid, Basingstoke, UK), not supplemented and supplemented with ceftriaxone $(1 \mathrm{mg} / \mathrm{L})$, and aerobically incubated for $24 \mathrm{~h}$ at $37^{\circ} \mathrm{C}$. The agar without ceftriaxone supplementation was used as a quality control of the sample growth to assess if negative growths on the supplemented agar were due to the ceftriaxone activity or because of a bad quality or degradation of the sample. All of the colonies grown on MacConkey agar with ceftriaxone were re-cultured on TSA agar in order 
to conduct bacterial identification, which was performed using conventional biochemical tests (oxidase, catalase, TSI, SIM, urease, citrate, and methyl red) and the API system (bioMérieux, Marcy l’Etoile, France).

\subsection{Antimicrobial Susceptibility Test}

All of the isolates identified from the MacConkey agar with ceftriaxone were stored at $-80{ }^{\circ} \mathrm{C}$ before antimicrobial susceptibility testing was performed using the disk diffusion method [17]. Briefly, one to four colonies were suspended in $5 \mathrm{~mL}$ of distilled sterile water to achieve a turbidity of 0.5 in the McFarland scale. The dilution was then seeded onto Mueller-Hinton (Oxoid, Basingstoke, UK) plates. Each isolate was tested for the following antimicrobial groups, using commercial disks: aminopenicillins (ampicillin (BD) and amoxicillin/clavulanic acid (Oxoid)), cephalosporins (ceftiofur (BD), ceftriaxone (BD), and cefquinome (CondaLab)), fluoroquinolones (ciprofloxacin (BD) and enrofloxacin (BD)), aminoglycosides (gentamicin (BD)), tetracyclines (tetracycline (BD)), macrolides (erythromycin (BD)), lincospectin (Oxoid), sulfamethoxazole/trimethoprim (BD), and chloramphenicol (BD). Then, based on the laboratory testing readings, isolates were classified as susceptible, intermediate, or resistant, as previously described [18-20].

For statistical assessments, all isolates that exhibited intermediate resistance were reclassified as resistant. In addition, multidrug resistance (MDR) was defined as resistance to at least one agent in three or more antimicrobial categories; extensive drug resistance (XDR) was defined as resistance to all but two of the tested antimicrobial categories; and finally, pan-drug resistance (PDR) was defined as resistance to all of the categories tested [21].

\subsection{Molecular Characterization of Antimicrobial Resistance Genes}

DNA was extracted by boiling the bacterial growth from the selective MacConkey Agar supplemented with ceftriaxone (1 mg/L) plates, as previously described [18,22]. Briefly, all the bacterial growths were diluted in $600 \mu \mathrm{L}$ of sterile distilled water, and $200 \mu \mathrm{L}$ of the dilution was then transferred to a new tube. Two-hundred microliters of sterile distilled water was added to each tube. The tubes were boiled at $100{ }^{\circ} \mathrm{C}$ in a water bath for $10 \mathrm{~min}$, and then centrifuged at $16,000 \times g$ for $5 \mathrm{~min}$. After centrifugation, the supernatant was recovered and stored at $-80^{\circ} \mathrm{C}$ until processing.

$\beta$-lactamase- $b l a_{\mathrm{TEM}}, b l a_{\mathrm{CTX}}, b l a_{\mathrm{SHV}}, b l a_{\mathrm{CMY}-1}, b l a_{\mathrm{CMY}-2}$, and $b l a_{\mathrm{OX}}$ - and plasmid mediated colistin-mcr1, mcr2, mcr3, mcr4, and mcr5-genes were assessed using previously described PCR protocols [10]. For all PCR assays, the master mix consisted of: $1 \times$ PCR Buffer, $0.2 \mathrm{mM}$ of each dNTP (Bioline, Livron-sur-Drôme, France), $3 \mathrm{mM}$ of MgCl2, $1 \mathrm{mM}$ of each primer, and $1 \mathrm{U}$ of Taq DNA Polymerase (Bioline, Livron-sur-Drôme, France). A final volume of $2.5 \mu \mathrm{L}$ of DNA was used in the PCR. In each reaction, positive and negative controls were included. The oligonucleotide sequence of primers is presented in Supplementary Table S1. Briefly, the PCR conditions were homogenized for all of the reactions as follows: $5 \mathrm{~min}$ at $94{ }^{\circ} \mathrm{C}$, followed by 25 cycles of $1 \mathrm{~min}$ at $94{ }^{\circ} \mathrm{C}, 1 \mathrm{~min}$ of annealing at $55^{\circ} \mathrm{C}$ and $1 \mathrm{~min}$ of extension at $72{ }^{\circ} \mathrm{C}$, and a final extension step of $7 \mathrm{~min}$ at $72{ }^{\circ} \mathrm{C}$. The controls for all genes were provided by the Veterinary Diagnostic Laboratory in Infectious Diseases of the Universitat Autònoma de Barcelona (UAB, Bellaterra, Spain).

Sanger DNA sequencing was conducted for bla $a_{\mathrm{TEM}}, b l a_{\mathrm{CTX}}, b l a_{\mathrm{SHV}}$, and bla $a_{\mathrm{OXA}}$ PCR products at the Genomic and Bioinformatics Service of the Universitat Autònoma de Barcelona (Spain). Sequences and chromatograms were manually explored to trim badquality bases with BioEdit 7.2. Once the assembly of the consensus sequences was conducted, both complete and partial sequences were aligned using the Clustal Omega program, and were finally blasted against the public database (National Center for Biotechnology Information, NCBI, Bethesda, MD, USA).

\subsection{Statistical Analysis}

All of the statistical analyses were performed with $\mathrm{R}$ software, version 3.6.0 [23]. The graphics for representing antimicrobial susceptibility were built using the "AMR" 
package [24]. Generalised lineal models were used to test the association between the presence of AMR genes (considered as the dependent variable) and different variables such as age, sex, month, population, density of the municipality, and cause of admission to WRC (considered as explanatory variables). First, bivariate analysis was used to individually test all the variables, and those with a $p$-value lower than 0.3 were selected. After that, correlation among predictor variables was evaluated by calculating the Spearman correlation coefficient, and variables with a coefficient higher than 0.5 were removed. Non-correlated variables were included in the multivariate analysis and the best model was selected based on the lowest Akaike Information Criteria (AIC) value [25]. The limit of significance of the $p$-value was set at 0.05 .

Maps were created using Quantum Gis software, version 3.18 [26]. To evaluate the areas with a higher probability of having animals carriers of AMR genes, cluster analysis was performed with SaTScan version 9.6, using a purely spatial scan analysis with a Bernoulli model [27]. The spatial scan analysis is based in the likelihood ratio statistic based on the number of observed and expected cases in the specific zone and the search for clusters using a variable circular window size to detect spatial clusters in large areas while controlling for the underlying population [27]. The number of Montecarlo simulations was set at 999 and $p$-values lower than 0.05 were considered statistically significant.

\section{Results}

Sixty seven out of the 114 wild hedgehog fecal samples analyzed (58.3\%) had a positive growth on agar supplemented with ceftriaxone. Pure cultures were obtained from most of the animals and 19 out of 67 hedgehogs presented more than one colony, identifying a total of 90 bacterial isolates. Klebsiella spp., principally Klebsiella pneumoniae ( $29 \%$ out of the total bacteria), was the most frequently detected microorganism (42.2\%), followed by E. coli (38.9\%). Other bacteria such as Citrobacter freundii (5.6\%), Serratia spp. (4.4\%), Proteus mirabilis (3.3\%), Enterobacter cloacae (2.2\%), and Shigella spp. (1.1\%) were also identified.

Regarding the presence of $\beta$-lactamase resistance, $36.8 \%$ of the animals $(42 / 114)$ were detected as carriers of AMR genes. Klebsiella spp. (59.6\%) was the agent with the highest proportion of resistance genes, followed by E. coli (34.6\%) and C. freundii (5.8\%). The frequency of genes and variants in the studied population was as follows: $19.3 \%$ bla $a_{\mathrm{CTX}-\mathrm{M}-15}, 10.5 \%$ bla $a_{\mathrm{SHV}-28}, 9.7 \%$ bla $a_{\mathrm{CMY}-1}$, and 8.8\% bla $a_{\mathrm{CMY}-2}$ (Table 1 ). In addition, 1.7\% of carbapenemases $b l a_{\mathrm{OXA}-48}$ was found in isolates of $K$. pneumoniae and E. coli from two different animals (Table 2). In contrast, no colistin mcr-plasmid-mediated resistance genes were detected in the tested animals.

Table 1. Number and frequencies of the samples positive for $\beta$-lactamase genes in European hedgehogs. CI, confidence intevals.

\begin{tabular}{|c|c|c|c|}
\hline AMR Gene & $\begin{array}{c}\text { Number of Animals with } \\
\text { AMR Gene }\end{array}$ & $\begin{array}{l}\text { Overall Frequency }(\%) \\
\text { CI } 95 \%(n=114)\end{array}$ & $\begin{array}{c}\text { Frequency }(\%) \text { and CI } 95 \% \\
\text { among Postive Animals }(n=42)\end{array}$ \\
\hline$b l a_{\mathrm{CTX}-\mathrm{M}-15}$ & 22 & $19.3(12.1-26.5)$ & $52.4(37.3-67.5)$ \\
\hline$b l a_{\mathrm{CTX}-\mathrm{M}-3}$ & 1 & $0.9(0-2.6)$ & $2.4(0-7)$ \\
\hline bla $_{\mathrm{SHV}-1}$ & 5 & $4.4(0.6-8.2)$ & $11.9(2.1-21.7)$ \\
\hline$b a_{\mathrm{SHV}-11}$ & 5 & $4.4(0.6-8.2)$ & $11.9(2.1-21.7)$ \\
\hline$b l a_{\mathrm{SHV}-12}$ & 3 & $2.6(0-5.6)$ & $7.1(0-14.9)$ \\
\hline$b l a_{\mathrm{SHV}-28}$ & 12 & $10.5(4.9-16.2)$ & $28.6(14.9-42.2)$ \\
\hline$b l a_{\mathrm{TEM}-1 \mathrm{~b}}$ & 5 & $4.4(0.6-8.2)$ & $11.9(2.1-21.7)$ \\
\hline bla $_{\mathrm{CMY}-1}$ & 11 & $9.7(4.2-15.1)$ & $26.2(12.9-39.5)$ \\
\hline$b l a_{\mathrm{CMY}-2}$ & 10 & $8.8(3.6-14)$ & $23.8(10.9-36.7)$ \\
\hline$b l a_{\mathrm{OXA}-48}$ & 2 & $1.8(0-4.2)$ & $4.8(0-11.2)$ \\
\hline
\end{tabular}


Table 2. Antimicrobial resistance genotypes and phenotypes of $\beta$-lactamase producing Enterobacteriaceae detected in wild European hedgehogs.

\begin{tabular}{|c|c|c|}
\hline Bacterial spp. & $\beta$-lactam Resistance Genes & AMR Phenotyping \\
\hline \multirow[t]{18}{*}{ Escherichia coli } & CTX-M-15, SHV-28 & $\mathrm{AMC}, \mathrm{E}, \mathrm{TET}$ \\
\hline & CTX-M-15 & CEFQ, E, CRO, XNL \\
\hline & CTX-M-15 & $\mathrm{E}$ \\
\hline & CTX-M-15 & AMP, CEFQ, ENO, E, LS, SXT, GM, CIP, CRO, C, XNL \\
\hline & CTX-M-15 & nt \\
\hline & CTX-M-15 & E, GM \\
\hline & CTX-M-15 & AMP, CEFQ, ENO, E, TET, CIP, CRO, XNL \\
\hline & CTX-M-15 & AMP, AMC, CEFQ, ENO, GM, E, SXT, TET, CIP, CRO, XNL \\
\hline & SHV-12 & AMP, AMC, CEFQ, ENO, GM, E, SXT, TET, CIP, CRO, XNL \\
\hline & SHV-11, OXA-48 & AMP, AMC, CEFQ, E, CRO, XNL \\
\hline & TEM-1b, CMY-2 & AMP, AMC, E, SXT, CRO, XNL \\
\hline & CMY-2 & $\mathrm{AMP}, \mathrm{ENO}, \mathrm{CIP}, \mathrm{CRO}, \mathrm{XNL}$ \\
\hline & CMY-2 & AMP, SXT, TET, CRO, XNL \\
\hline & CMY-2 & $\mathrm{AMP}, \mathrm{CRO}, \mathrm{XNL}$ \\
\hline & CMY-2 & AMP, ENO, E, LS, TET, XNL \\
\hline & CMY-2 & AMP, AMC, ENO, E, LS, SXT, TET, CIP, CRO, XNL \\
\hline & CMY-2 & $\mathrm{AMP}, \mathrm{AMC}, \mathrm{E}, \mathrm{CRO}, \mathrm{XNL}$ \\
\hline & CMY-2 & AMP, AMC, E, TET \\
\hline \multirow[t]{9}{*}{ Klebsiella spp. } & SHV-28, TEM-1b, CMY-2 & AMP, AMC, ENO, GM, E, LS, SXT, TET, CIP, C \\
\hline & SHV, CMY-1 & AMP, ENO, E, LS, SXT, TET, CIP, C \\
\hline & CTX-M-15, SHV-1 & AMP, AMC, CEFQ, ENO, E, SXT, TET, CIP, CRO, XNL \\
\hline & CMY-2 & AMP, AMC, CEFQ, ENO, E, SXT, TET, CIP, CRO, C, XNL \\
\hline & CTX-M-15, SHV-28, CMY-1 & AMP, AMC, CEFQ, ENO, GM, E, SXT, TET, CIP, CRO, XNL \\
\hline & CTX-M-15, SHV-11, CMY-1 & AMP, AMC, CEFQ, ENO, E, SXT, TET, CIP, CRO, XNL \\
\hline & CTX-M-15, SHV-11, CMY-1 & AMP, AMC, CEFQ, ENO, E, SXT, TET, CIP, CRO, XNL \\
\hline & CTX-M-15, SHV-11 & AMP, CEFQ, ENO, E, TET, CIP, CRO, XNL \\
\hline & CTX-M-15 & AMP, AMC, CEFQ, ENO, E, SXT, TET, CIP, CRO, XNL \\
\hline \multirow[t]{21}{*}{ K. pneumoniae } & CTX-M-15, CMY-1 & AMP, AMC, CEFQ, ENO, E, SXT, TET, CIP, CRO, XNL \\
\hline & CTX-M-15, SHV-28, CMY-1 & AMP, AMC, CEFQ, ENO, GM, E, SXT, TET, CIP, CRO, XNL \\
\hline & CTX-M-15, SHV-28, CMY-1 & AMP, AMC, CEFQ, ENO, GM, E, SXT, TET, CIP, CRO, XNL \\
\hline & CMY-1, OXA-48 & AMP, AMC, ENO, E, LS, SXT, CIP, XNL \\
\hline & SHV-28, CMY-1 & AMP, AMC, ENO, E, LS, SXT, TET, CIP, XNL \\
\hline & CTX-M-15 & AMP, AMC, CEFQ, ENO, GM, E, SXT, TET, CIP, CRO, XNL \\
\hline & CTX-M-15, SHV-28 & AMP, AMC, CEFQ, ENO, GM, E, SXT, TET, CIP, CRO, XNL \\
\hline & CTX-M-15, SHV-28 & AMP, AMC, CEFQ, ENO, GM, E, LS, SXT, TET, CIP, CRO, XNL \\
\hline & CTX-M-15, SHV-28 & $\mathrm{AMP}, \mathrm{AMC}, \mathrm{E}$ \\
\hline & CTX-M-15, SHV-28 & AMP, AMC, ENO, E, TET, CRO, XNL \\
\hline & CTX-M-15, SHV-28 & nt \\
\hline & SHV-1 & AMP, AMC, CEFQ, ENO, E, SXT, TET, CIP, CRO, C, XNL \\
\hline & SHV-1 & AMP, AMC, ENO, E, CRO, XNL \\
\hline & SHV-1 & $\mathrm{AMP}, \mathrm{AMC}, \mathrm{ENO}, \mathrm{E}, \mathrm{XNL}$ \\
\hline & CTX-M-15, SHV-28 & AMP, AMC, CEFQ, ENO, GM, E, SXT, TET, CIP, CRO, XNL \\
\hline & CTX-M-15, SHV-28, CMY-1, CMY-2 & AMP, AMC, CEFQ, ENO, GM, E, SXT, CIP, CRO, XNL \\
\hline & CTX-M-15, SHV-1, TEM-1b, CMY-1, CMY-2 & AMP, AMC, CEFQ, ENO, GM, E, SXT, TET, CIP, CRO, XNL \\
\hline & SHV-28 & AMP, AMC, CEFQ, ENO, GM, E, SXT, TET, CIP, CRO, XNL \\
\hline & SHV-12 & AMP, AMC, CEFQ, ENO, E, SXT, TET, CIP, CRO, XNL \\
\hline & SHV-1, TEM-1b & AMP, AMC, CEFQ, ENO, GM, E, SXT, TET, CIP, CRO, XNL \\
\hline & SHV-1 & nt \\
\hline K. oxytoca & CTX-M-3 & AMP, AMC, CEFQ, ENO, E, CIP, CRO, XNL \\
\hline \multirow[t]{2}{*}{ Citrobacter freundii } & SHV-12, CMY-2 & AMP, AMC, CEFQ, ENO, E, LS, SXT, TET, CIP, CRO, XNL \\
\hline & $\begin{array}{l}\text { TEM-1b, CMY-2 } \\
\text { CMY-2 }\end{array}$ & AMP, AMC, CEFQ, ENO, GM, E, TET, CIP, CRO, XNL \\
\hline
\end{tabular}

AMP—ampicillin; AMC—amoxicillin + clavulanic acid; CEFQ—cefquinome; ENO—enrofloxacin; GM-gentamicin; E-erythromycin; LS-lincospectin; SXT—-trimetoprim + sulphametoxazol; TET, Tetracycline; CIP-ciprofloxacin; CRO-ceftriaxone; XNL—ceftiofur; C-cloramphenicol; nt—not tested.

Regarding the AST results, almost 52\% (27/52) of the isolates showed an MDR phenotype and $30.8 \%$ had an extended (XDR) profile (Table 2 ). Interestingly, a high proportion of the bacterial isolates presented more than one AMR gene, especially within the genus Klebsiella, in which $67.7 \%(21 / 31)$ of the isolates presented two or more $\beta$-lactamase genes. The most common combination was $b l a_{\mathrm{CTX}-\mathrm{M}-15}$ and $b l a_{\mathrm{SHV}-28}$, which was present in $21.2 \%$ 
$(11 / 52)$ of the overall isolates, and principally in K. pneumoniae, for which $84.6 \%$ of the isolates carried AMR genes, with up to 4-5 genes in some cases (Table 2).

$\mathrm{AMP}$-ampicillin; AMC — amoxicillin + clavulanic acid; CEFQ—cefquinome; ENOenrofloxacin; GM — gentamicin; E-erythromycin; LS - lincospectin; SXT-trimetoprim + sulphametoxazol; TET, Tetracycline; CIP—ciprofloxacin; CRO—ceftriaxone; XNL—ceftiofur; C-cloramphenicol; nt-not tested.

The results of the phenotypic antimicrobial susceptibility testing showed high levels of resistance in most of the tested antimicrobials (Figure 2). It is important to note the highest levels of resistance were observed among the Klebsiella isolates, especially for quinolones, third and fourth generation cephalosporines, trimethoprim/sulphametoxazol, and tetracyclines.

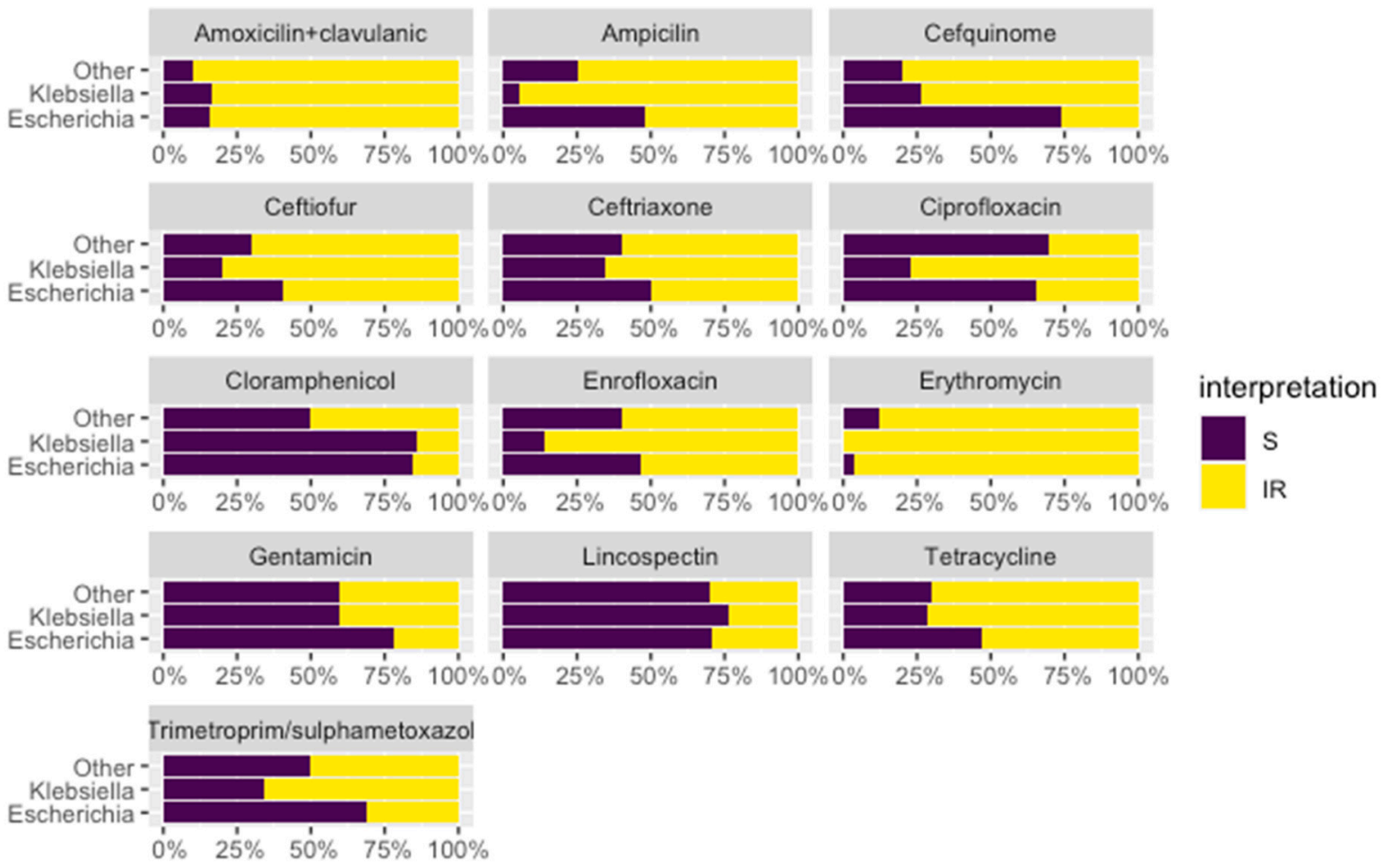

Figure 2. Antimicrobial susceptibility phenotype of the different isolates. Interpretation: S—sensitive (in purple); Iintermediate and $\mathrm{R}$-resistant (in yellow).

A generalised linear model was created to test the association between the presence of AMR genes and different variables, such as cause of hospitalization, human density of the zone, sex, age, and month of collection of the sample, but no variable was found to be statistically significant. As some animals were carriers from more than one bacterium, species could not be included as an explanatory variable. So, to evaluate the possible association of the variables explained before and the presence of the most prevalent genus, two specific generalised linear model were created just for animals that were carriers of Klebsiella spp and E. coli. However, again, no variable was found to be statistically significant.

Odd ratios and $p$-values of the models are presented on Supplementary Tables S2 and S3. Regarding animal distribution, at least one animal from the sampled regions was positive for $\beta$-lactams resistance genes (Figure 3). 


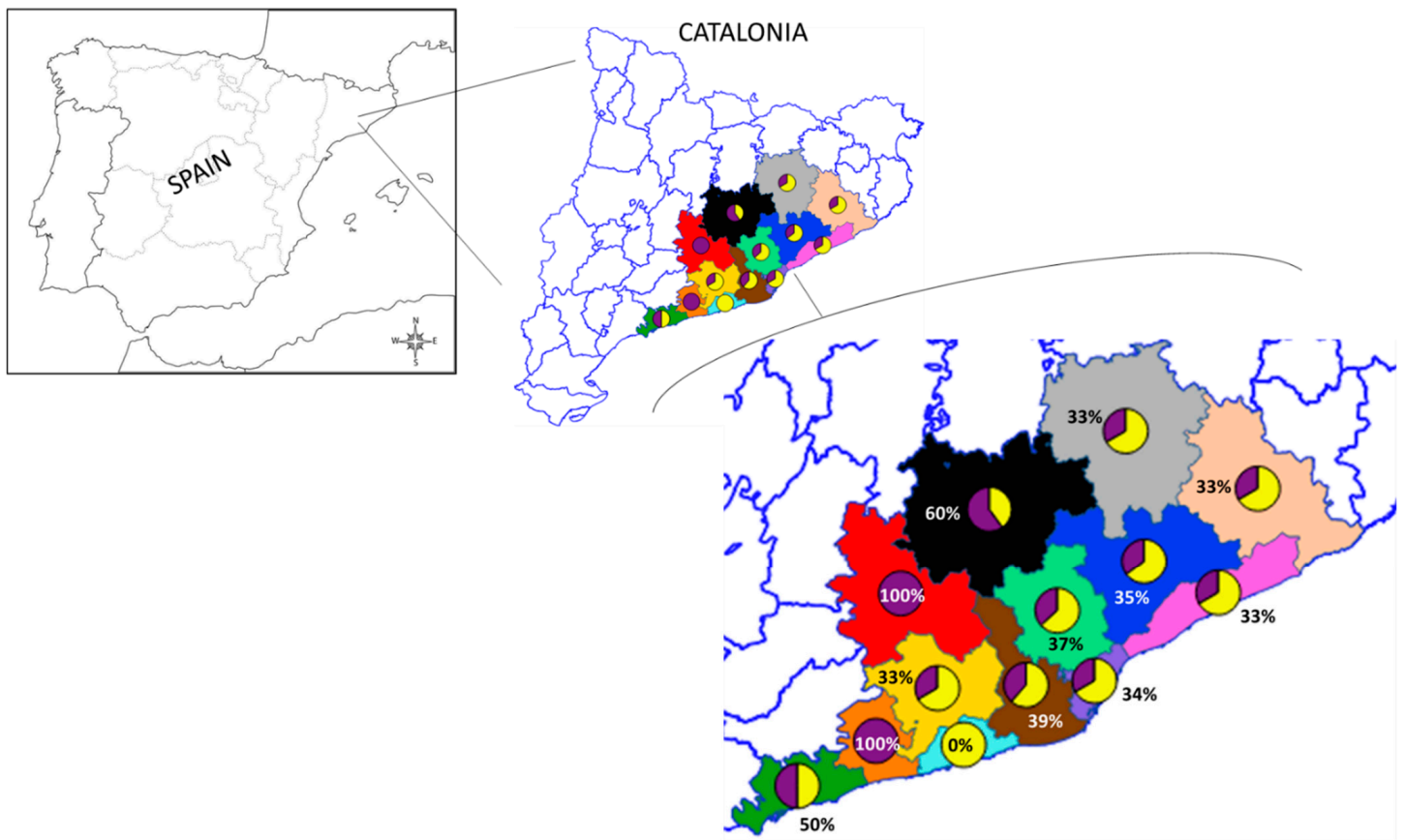

Figure 3. The map shows the counties where hedgehogs were found. Pie charts represent the occurrence of wild hedgehogs positive for AMR genes from the total number of sampled individuals for the corresponding study areas: green-Tarragonès $(n=2)$; orange-Baix Penedès $(n=1)$; azure—Garraf $(n=2)$; yellow-Alt Penedès $(n=3)$; brown-Baix Llobregat $(n=13)$; red-Anoia $(n=1)$; Black—Bages $(n=5)$; mint-Vallès Occidental $(n=38)$; purple-Barcelonès $(n=17)$; blue-Vallès Oriental $(n=17)$; pink-Maresme $(n=6)$; beige—Selva $(n=3)$; grey-Osona $(n=3)$. Pie charts: purple-positive; yellow-negative.

In Figure 4, a map with the location of wild hedgehogs positive for AMR genes is presented. Most of the sampled animals were found in highly populated areas of Catalonia. The scan statistics did not detect any significant cluster of animals carrying AMR genes, neither were there statistically significant differences in the frequency of positive animals among the regions.

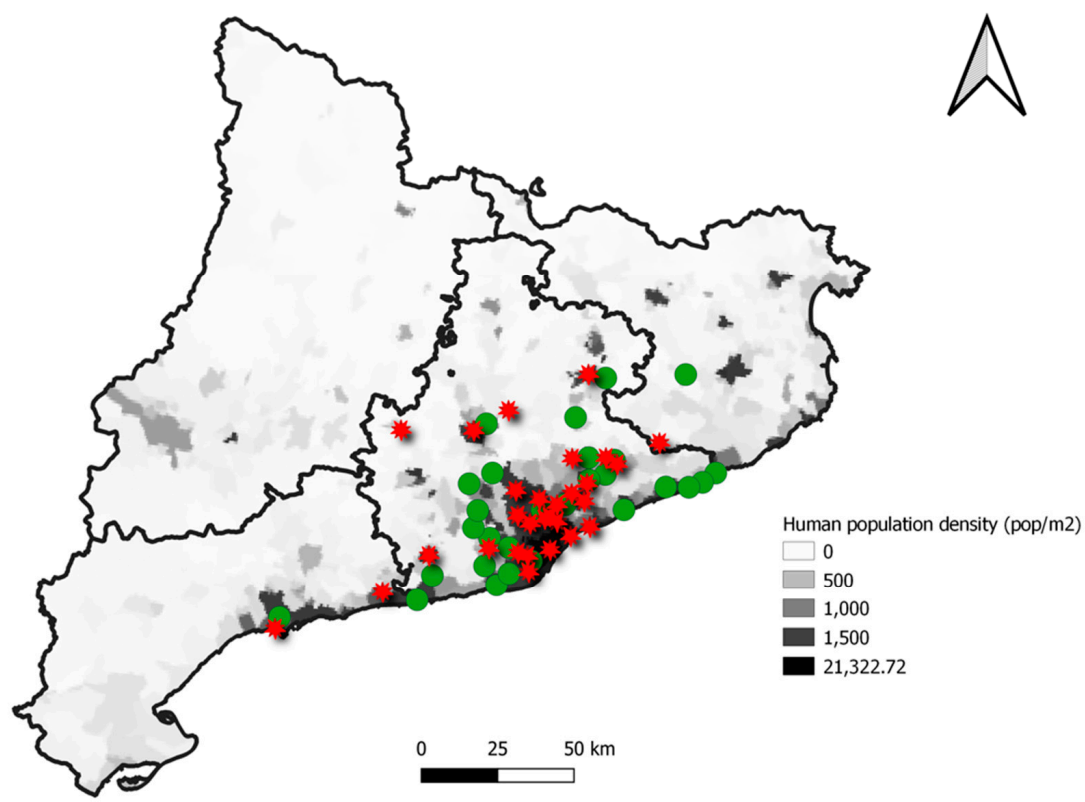

Figure 4. Localization and distribution of the hedgehogs included in the study according to the presence of at least one AMR gene (red star) or their absence (green dot) in each municipality over the human population density of each zone. 


\section{Discussion}

In this study, a high occurrence of $\beta$-lactamase resistance genes has been reported in a wild population of European hedgehogs coming from urbanized areas of Catalonia. To our knowledge, this is the first description of $\beta$-lactam resistant enterobacteria in wild hedgehogs. Sixty seven out of 114 faecal samples (57.8\%) had growths in ceftriaxone supplemented agar, but AMR genes were detected in 42 of them (36.8\%). Regarding the bacterial isolates, a total of 90 bacterial isolates were identified from those 67 analysed animals, and AMR genes were detected in 52 isolates. Thus, in line with other studies [28,29], we observed that some of the AMRB did not have any of the AMR genes. This could be explained by the possible existence of other mechanisms of resistance such as chromosomal mechanisms that were not included as a target of this study.

Interestingly, $36.8 \%$ of the animals were detected as carriers of AMR genes, with a special occurrence of human nosocomial bacteria harbouring ESBL, AmpC, and OXA genes. Moreover, Klebsiella pneumoniae was the bacteria with the highest proportion of resistance genes, followed by $E$. coli and $C$. freundii. The most frequently detected genes were $b a_{\mathrm{CTX}-\mathrm{M}-15}(19.3 \%)$, bla $a_{\mathrm{SHV}-28}(10.5 \%)$, bla $a_{\mathrm{CMY}-1}(9.7 \%)$, and $b a_{\mathrm{CMY}-2}(8.8 \%)$. In addition, carbapenemases $b l a_{\mathrm{OXA}-48}$ genes were found in two animals. It is interesting to remark that more than half of the enterobacteria presented a MDR phenotype, with an extended profile (XDR) in $30 \%$ of the isolates.

According to the World Health Organization and the World Organization for Animal Health, third- and fourth-generation cephalosporins are critically important antibiotics to treat infection diseases in humans [30] and animals [31]. However, in the last decades, acquired resistance to $\beta$-lactams, mainly mediated by extended-spectrum beta-lactamase and AmpC $\beta$-lactamases, such as cephalosporinases, has been widely reported worldwide from humans, livestock, companion animals, the environment, and wildlife [32,33]. The results obtained in this study in wild hedgehogs dwelling in highly populated areas of Catalonia corroborate this wide distribution of $\beta$-lactam resistance genes. In fact, a high proportion of the bacterial isolates, especially K. pneumoniae, presented two or more $\beta$-lactamase genes and a phenotype of resistance to third- and fourth-generation cephalosporins among other compounds.

The presence of $\beta$-lactamase resistance genes has been historically analysed using E. coli as a marker in livestock [34] and wildlife [35-37]. Regarding wildlife, the presence of ESBL genes has been reported principally in wild birds [38-40], but also in other species such as bats [41], wild boars [29], and fish [42]. The most commonly detected ESBL genes are CTX-M-1, CTX-M-14, and CTX-M-15, which are also found frequently in hospital settings, suggesting a relationship between bacteria from wildlife and health-care facilities [33]. Interestingly, hedgehogs from this study harbouring the CTX-M group were all classified with the CTX-M-15 variant. This variant has been described in the high risk clone ST131 of E. coli, which generates nosocomial issues worldwide [43]. Within the SHV group, we found a variety of variants distributed in all of the regions sampled, with SHV-28 being the most frequent one. The combination of CTX-M-15 with SHV-28 was the most repeated association, found principally in K. pneumoniae isolates. This association, when located in Klebsiella species, has been related with the high risk clone ST15, which is an emerging cause of nosocomial infections [44].

The AmpC $\beta$-lactamase genes CMY- 1 and CMY-2 were detected in the tested hedgehogs. As these genes can be either acquired by plasmids or can be chromosomally selected [44], it is difficult to attribute the presence of CMY-1 and -2 in these animals as a result of direct environmental contamination. Similarly, the genetic resistance of $C$. freundii isolates found in three animals is usually originated at a chromosomal level. However, most of the bacteria carrying AmpC genes found in the wild hedgehogs of this study were Klebsiella spp. and E. coli, which usually acquire resistance genes by plasmids [45].

Regarding other families of antibiotics, plasmid mediated colistin resistance genes were also analysed. Colistin is considered a last therapeutic option in human medicine and is widely used in cases of infections caused by ESBL bacteria [46]. However, the coexistence 
of resistance genes to $\beta$-lactamase and to colistin has been detected in humans [47], livestock [48], and wild birds [49]. It has been speculated that colistin use in animal production, and particularly in the pig industry, could be the original source of these genes [22]. In this study, none of the tested animals presented colistin (mcr-1 to -5) resistance genes, but this is an expected finding as most of the tested animals came from urbanized areas with a low risk of contact with residues from pig production. However, the inclusion of a larger sample size with hedgehogs from regions with a high swine population density, such as Osona, in the analysis, could help to improve the odds of detecting these colistin resistance genes. On the other hand, the emergence of resistance to carbapenems-last resort drugs used in hospital settings for the treatment of severe infections caused by $\beta$-lactam resistant enterobacteria-has compromised the therapeutic options in human health [50]. Specially, the OXA- 48 variant of carbapenemases is becoming highly prevalent in human clinical infections in Europe [51]. This high prevalence in human settings could explain the $1.7 \%$ of OXA-48 frequency in the hedgehog populations of urban surroundings. As carbapenems are not allowed in food animals, the increasing presence of carbapenemases genes in livestock [52], companion animals [53], and wildlife animals [54] is alarming evidence of the anthropogenic environmental contamination.

The spatial analysis showed that the frequency and distribution of hedgehogs carrying AMR genes was similar in the study area. However, it is important to mention that most of the animals included in this study came from highly urbanized regions, because there is more chance of them being found and taken to the wildlife centre. In addition, the hedgehog population density has increased in urban areas compared with rural zones (26), so sampling animals from these zones can be more difficult. Finally, as most of the animals came from highly populated regions, it is reasonable to speculate that the close contact with human areas leads to the transmission of AMR genes to wildlife, because they either inhabit and/or feed in an anthropogenic environment [55].

Regarding the AMR phenotype, it is important to remark that, although the AST was only performed on isolates grown on MacConkey agar supplemented with ceftriaxone, in order to focus on ESBLs, some of these strains showed a sensitive phenotype to ceftriaxone after long storage at $-80^{\circ} \mathrm{C}$. These long periods of freezing could affect both the viability of some of the strains and the loss of these genes that confer resistance.

The high frequency of hedgehogs carrying $\beta$-lactamase resistance genes in this study is a cause of concern, because these animals have never been treated with an antibiotic; thus, the presence of AMR genes must be related to exposure to sewage water or soils contaminated with AMR bacteria and/or antimicrobial residues. Sewage treatment plants are not completely efficient at removing all antibiotic residues and AMR bacteria [56], and contaminated water is spread into rivers and seas. Moreover, livestock manure is applied to land and can also contain it [57], enriching the resistome in both soils and earthworms [58]. Earthworms, a key biological component of soil, have been shown to contribute to spreading AMR, as they can acquire antibiotics directly from the soil [55]. Considering that most of the hedgehog's diet is based on earthworms and other invertebrates, hedgehogs are more directly exposed to these antibiotic substances and resistance genes. Hence, the results of this study suggest that hedgehogs are good sentinels of AMR environmental pollution, especially in highly populated areas with high human activity.

Furthermore, the presence of wild hedgehogs carrying MDR bacteria as clinical patients at the WRC might compromise the effectiveness of antimicrobial treatments in these animals, and it can also represent a zoonotic risk for staff and the general population who come into contact with them.

\section{Conclusions}

This study reveals a high prevalence of human nosocomial-like bacteria with $\beta$ lactamase resistance genes in wild hedgehogs inhabiting highly populated zones in Catalonia. It is crucial to raise awareness about the strong interconnection between habitats and compartments induced by multiple exchange routes, which implies that AMR issues 
must be tackled under the One Health approach. Further studies are needed to confirm the relatedness of cephalosporin resistant Enterobacteriaceae strains found in wild hedgehogs as well as those that cause concern in human hospitals at a regional level.

Supplementary Materials: The following are available online at https:/ / www.mdpi.com/article/ 10.3390/ani11102837/s1. Table S1: Oligonucleotides used for the detection of ESBL/AmpC and colistin-resistance genes in this study, Table S2: Odd-ratios and p-values of bivariate generalized linear models, Table S3: Odd-ratios and p-values of multivariate generalized linear models.

Author Contributions: Conceptualization, R.A.M.-L. and L.D.; methodology, B.G., E.O., R.A.M.L. and L.D.; software, B.G. and A.A.; validation, L.D.; formal analysis, B.G., L.A., C.S. and N.R.; investigation, L.D.; resources, L.D.; data curation, B.G., L.A., C.S., N.R. and L.D.; writing-original draft preparation, B.G. and L.D.; writing-review and editing, B.G., A.A., E.O., R.A.M.-L. and L.D.; supervision, L.D.; funding acquisition, L.D. All authors have read and agreed to the published version of the manuscript.

Funding: Biel Garcias was supported by Departament de Recerca i Universitats de la Generalitat de Catalunya (FI-SDUR 2020).

Institutional Review Board Statement: The authors only collected samples. Therefore, the research did not cause any harm or suffering to any animals.

Informed Consent Statement: Not applicable.

Data Availability Statement: Data will be made available upon reasonable request to the corresponding author.

Acknowledgments: The authors are grateful to the Torreferrussa WRC staff for their dedication to rehabilitating the animals.

Conflicts of Interest: The authors do not have any conflict of interest.

\section{References}

1. Karesh, W.B.; Dobson, A.; Lloyd-Smith, J.O.; Lubroth, J.; Dixon, M.A.; Bennett, M.; Aldrich, S.; Harrington, T.; Formenty, P.; Loh, E.H.; et al. Ecology of zoonoses: Natural and unnatural histories. Lancet 2012, 380, 1936-1945. [CrossRef]

2. Ebrahim, M.; Gravel, D.; Thabet, C.; Abdesselam, K.; Paramalingam, S.; Hyson, C. Antimicrobial use and antimicrobial resistance trends in Canada: 2014. Can. Commun. Dis. Rep. 2016, 42, 227-231. [CrossRef] [PubMed]

3. Arnold, K.E.; Williams, N.J.; Bennett, M. 'Disperse abroad in the land': The role of wildlife in the dissemination of antimicrobial resistance. Biol. Lett. 2016, 12, 20160137. [CrossRef] [PubMed]

4. Huijbers, P.M.C.; Blaak, H.; De Jong, M.C.M.; Graat, E.A.M.; Vandenbroucke-Grauls, C.M.J.E.; De Roda Husman, A.M. Role of the Environment in the Transmission of Antimicrobial Resistance to Humans: A Review. Environ. Sci. Technol. 2015, 49, 11993-12004. [CrossRef] [PubMed]

5. Swift, B.M.C.; Bennett, M.; Waller, K.; Dodd, C.; Murray, A.; Gomes, R.L.; Humphreys, B.; Hobman, J.L.; Jones, M.A.; Whitlock, S.E.; et al. Anthropogenic environmental drivers of antimicrobial resistance in wildlife. Sci. Total Environ. 2019, 649, 12-20. [CrossRef] [PubMed]

6. Carroll, D.; Wang, J.; Fanning, S.; McMahon, B.J. Antimicrobial Resistance in Wildlife: Implications for Public Health. Zoonoses Public Health 2015, 62, 534-542. [CrossRef]

7. Dolejska, M.; Cizek, A.; Literak, I. High prevalence of antimicrobial-resistant genes and integrons in Escherichia coli isolates from Black-headed Gulls in the Czech Republic. J. Appl. Microbiol. 2007, 103, 11-19. [CrossRef]

8. Hoefer, H.L. Hedgehogs. Vet. Clin. N. Am. Small Anim. Pract. 1994, 24, 113-120. [CrossRef]

9. Hubert, P.; Julliard, R.; Biagianti, S.; Poulle, M.-L. Ecological factors driving the higher hedgehog (Erinaceus europeaus) density in an urban area compared to the adjacent rural area. Landsc. Urban Plan. 2011, 103, 34-43. [CrossRef]

10. Darwich, L.; Vidal, A.; Seminati, C.; Albamonte, A.; Casado, A.; López, F.; Molina-López, R.A.; Migura-Garcia, L. High prevalence and diversity of extended-spectrum $\beta$-lactamase and emergence of OXA-48 producing Enterobacterales in wildlife in Catalonia. PLoS ONE 2019, 14, e210686. [CrossRef]

11. Di Francesco, A.; Renzi, M.; Borel, N.; Marti, H.; Salvatore, D. Detection of Tetracycline Resistance Genes in European Hedgehogs (Erinaceus europaeus) and Crested Porcupines (Hystrix cristata). J. Wildl. Dis. 2020, 56, 219-223. [CrossRef]

12. Rasmussen, S.L.; Larsen, J.; van Wijk, R.E.; Jones, O.R.; Berg, T.B.; Angen, Ø.; Larsen, A.R. European hedgehogs (Erinaceus europaeus) as a natural reservoir of methicillin-resistant Staphylococcus aureus carrying mecC in Denmark. PLoS ONE 2019, 14, e0222031. [CrossRef]

13. Bengtsson, B.; Persson, L.; Ekström, K.; Unnerstad, H.E.; Uhlhorn, H.; Börjesson, S. High occurrence of mecC-MRSA in wild hedgehogs (Erinaceus europaeus) in Sweden. Vet. Microbiol. 2017, 207, 103-107. [CrossRef] 
14. Literak, I.; Dolejska, M.; Radimersky, T.; Klimes, J.; Friedman, M.; Aarestrup, F.M.; Hasman, H.; Cizek, A. Antimicrobialresistant faecal Escherichia coli in wild mammals in central Europe: Multiresistant Escherichia coli producing extended-spectrum beta-lactamases in wild boars. J. Appl. Microbiol. 2010, 108, 1702-1711. [CrossRef]

15. Spanish, R.D. 1201/2005 of the Ministry of Presidency of Spain (10th October 2005). BOE 21st October 2005. Available online: www.boe.es/boe/dias/2005/10/21/pdfs/A34367-34391.pdf (accessed on 24 May 2021).

16. Molina-López, R.A.; Casal, J.; Darwich, L. Causes of morbidity in wild raptor populations admitted at a wildlife rehabilitation centre in Spain from 1995-2007: A long term retrospective study. PLoS ONE 2011, 6, e24603. [CrossRef]

17. Bauer, A.W.; Kirby, W.M.; Sherris, J.C.; Turck, M. Antibiotic susceptibility testing by a standardized single disk method. Am. J. Clin. Pathol. 1966, 45, 493-496. [CrossRef] [PubMed]

18. Vidal, A.; Martín-Valls, G.E.; Tello, M.; Mateu, E.; Martín, M.; Darwich, L. Prevalence of enteric pathogens in diarrheic and non-diarrheic samples from pig farms with neonatal diarrhea in the North East of Spain. Vet. Microbiol. 2019, $237,108419$. [CrossRef] [PubMed]

19. CLSI. Performance Standards for Antimicrobial Susceptibility Testing, 29th ed.; CLSI Supplement M100; Clinical and Laboratory Standards Institute: Wayne, PA, USA, 2019.

20. CLSI. Performance Standards for Antimicrobial Disk and Dilution Susceptibility Tests for Bacteria Isolated from Animals, 4th ed.; CLSI Supplement VET08; Clinical and Laboratory Standards Institute: Wayne, PA, USA, 2019.

21. Magiorakos, A.-P.; Srinivasan, A.; Carey, R.B.; Carmeli, Y.; Falagas, M.E.; Giske, C.G.; Harbarth, S.; Hindler, J.F.; Kahlmeter, G.; Olsson-Liljequist, B.; et al. Multidrug-resistant, extensively drug-resistant and pandrug-resistant bacteria: An international expert proposal for interim standard definitions for acquired resistance. Clin. Microbiol. Infect. Off. Publ. Eur. Soc. Clin. Microbiol. Infect. Dis. 2012, 18, 268-281. [CrossRef] [PubMed]

22. Aguirre, L.; Vidal, A.; Seminati, C.; Tello, M.; Redondo, N.; Darwich, L.; Martín, M. Antimicrobial resistance profile and prevalence of extended-spectrum beta-lactamases (ESBL), AmpC beta-lactamases and colistin resistance (mcr) genes in Escherichia coli from swine between 1999 and 2018. Porc. Health Manag. 2020, 6, 4-9. [CrossRef] [PubMed]

23. R Core Team. R: A Language and Environment for Statistical Computing. R Found. Stat. Comput. 2020. Available online: http:/ / www.r-project.org/index.html (accessed on 24 May 2021).

24. Berends, M.S.; Luz, C.F.; Friedrich, A.W.; Sinha, B.N.M.; Albers, C.J.; Glasner, C. AMR—An R Package for Working with Antimicrobial Resistance Data. bioRxiv 2021, 810622. [CrossRef]

25. Akaike, H. A new look at the statistical model identification. IEEE Trans. Automat. Contr. 1974, 19, 716-723. [CrossRef]

26. QGIS Development Team. Open Source Geospatial Foundation Project. 2020. Available online: http:/ / qgis.osgeo.org (accessed on 24 May 2021).

27. Kulldorff, M. A spatial scan statistic. Commun. Stat. - Theory Methods 1997, 26, 1481-1496. [CrossRef]

28. Petrocchi-Rilo, M.; Gutiérrez-Martín, C.-B.; Pérez-Fernández, E.; Vilaró, A.; Fraile, L.; Martínez-Martínez, S. Antimicrobial Resistance Genes in Porcine Pasteurella multocida Are Not Associated with Its Antimicrobial Susceptibility Pattern. Antibiotics 2020, 9, 614. [CrossRef] [PubMed]

29. Darwich, L.; Seminati, C.; López-Olvera, J.R.; Vidal, A.; Aguirre, L.; Cerdá, M.; Garcias, B.; Valldeperes, M.; Castillo-Contreras, R.; Migura-Garcia, L.; et al. Detection of Beta-Lactam-Resistant Escherichia coli and Toxigenic Clostridioides difficile Strains in Wild Boars Foraging in an Anthropization Gradient. Animals 2021, 11, 1585. [CrossRef]

30. World Health Organization (WHO). List of Critically Important Antimicrobials for Human Medicine (WHO CIA List) 6th Rev. 2018. Available online: https://www.who.int/publications/i/item/9789241515528 (accessed on 31 May 2021).

31. World Organization for Animal Health (OIE). OIE List of Antimicrobial Agents of Veterinary Importance; Paris, France, 2018. Available online: https://www.google.com/url?sa=t\&rct=j\&q=\&esrc=s\&source=web\&cd=\&ved=2ahUKEwilkvic4 qHzAhWRA4gKHVkvAzMQFnoECAkQAQ\&url=https\%3A\%2F\%2Fwww.oie.int\%2Fapp\%2Fuploads\%2F2021\%2F03\%2Faoie-list-antimicrobials-may2018.pdf\&usg=AOvVaw1pz9D_mxiyYAaRookHeCZh (accessed on 31 May 2021).

32. Liakopoulos, A.; Olsen, B.; Geurts, Y.; Artursson, K.; Berg, C.; Mevius, D.J.; Bonnedahl, J. Molecular Characterization of ExtendedSpectrum-Cephalosporin-Resistant Enterobacteriaceae from Wild Kelp Gulls in South America. Antimicrob. Agents Chemother. 2016, 60, 6924-6927. [CrossRef] [PubMed]

33. Palmeira, J.D.; Cunha, M.V.; Carvalho, J.; Ferreira, H.; Fonseca, C.; Torres, R.T. Emergence and Spread of Cephalosporinases in Wildlife: A Review. Animals 2021, 11, 1765. [CrossRef] [PubMed]

34. Vidal, A.; Aguirre, L.; Seminati, C.; Tello, M.; Redondo, N.; Martín, M.; Darwich, L. Antimicrobial Resistance Profiles and Characterization of Escherichia coli Strains from Cases of Neonatal Diarrhea in Spanish Pig Farms. Vet. Sci. 2020, 7, 48. [CrossRef] [PubMed]

35. Murphy, R.; Palm, M.; Mustonen, V.; Warringer, J.; Farewell, A.; Parts, L.; Moradigaravand, D. Genomic Epidemiology and Evolution of Escherichia coli in Wild Animals in Mexico. mSphere 2021, 6, e00738-20. [CrossRef]

36. Bonardi, S.; Cabassi, C.S.; Longhi, S.; Pia, F.; Corradi, M.; Gilioli, S.; Scaltriti, E. Detection of Extended- Spectrum Beta-Lactamase producing Escherichia coli from mesenteric lymph nodes of wild boars (Sus scrofa). Ital. J. Food Saf. 2018, 7, 7707. [CrossRef]

37. Velhner, M.; Todorović, D.; Grego, E.; Jovčić, B.; Prunić, B.; Stojanov, I.; Kehrenberg, C. Fluoroquinolone-resistant and extendedspectrum beta-lactamase producing Escherichia coli isolates from free-living wild animals. Vet. Microbiol. 2018, 223, 168-172. [CrossRef] 
38. Alcalá, L.; Alonso, C.A.; Simón, C.; González-Esteban, C.; Orós, J.; Rezusta, A.; Ortega, C.; Torres, C. Wild Birds, Frequent Carriers of Extended-Spectrum $\beta$-Lactamase (ESBL) Producing Escherichia coli of CTX-M and SHV-12 Types. Microb. Ecol. 2016, 72, 861-869. [CrossRef]

39. Zurfluh, K.; Albini, S.; Mattmann, P.; Kindle, P.; Nüesch-Inderbinen, M.; Stephan, R.; Vogler, B.R. Antimicrobial resistant and extended-spectrum $\beta$-lactamase producing Escherichia coli in common wild bird species in Switzerland. Microbiologyopen 2019, 8, e845. [CrossRef]

40. Hasan, B.; Laurell, K.; Rakib, M.M.; Ahlstedt, E.; Hernandez, J.; Caceres, M.; Järhult, J.D. Fecal Carriage of Extended-Spectrum $\beta$-Lactamases in Healthy Humans, Poultry, and Wild Birds in León, Nicaragua-A Shared Pool of bla(CTX-M) Genes and Possible Interspecies Clonal Spread of Extended-Spectrum $\beta$-Lactamases-Producing Escherichia coli. Microb. Drug Resist. 2016, 22, 682-687. [CrossRef]

41. Benavides, J.A.; Shiva, C.; Virhuez, M.; Tello, C.; Appelgren, A.; Vendrell, J.; Solassol, J.; Godreuil, S.; Streicker, D.G. Extendedspectrum beta-lactamase-producing Escherichia coli in common vampire bats Desmodus rotundus and livestock in Peru. Zoonoses Public Health 2018, 65, 454-458. [CrossRef]

42. Sellera, F.P.; Fernandes, M.R.; Moura, Q.; Carvalho, M.P.N.; Lincopan, N. Extended-spectrum- $\beta$-lactamase (CTX-M)-producing Escherichia coli in wild fishes from a polluted area in the Atlantic Coast of South America. Mar. Pollut. Bull. 2018, 135, 183-186. [CrossRef]

43. Nicolas-Chanoine, M.-H.; Bertrand, X.; Madec, J.-Y. Escherichia coli ST131, an intriguing clonal group. Clin. Microbiol. Rev. 2014, 27, 543-574. [CrossRef]

44. Han, Y.; Huang, L.; Liu, C.; Huang, X.; Zheng, R.; Lu, Y.; Xia, W.; Ni, F.; Mei, Y.; Liu, G. Characterization of Carbapenem-Resistant Klebsiella pneumoniae ST15 Clone Coproducing KPC-2, CTX-M-15 and SHV-28 Spread in an Intensive Care Unit of a Tertiary Hospital. Infect. Drug Resist. 2021, 14, 767-773. [CrossRef] [PubMed]

45. Bush, K. Past and present perspectives on $\beta$-lactamases. Antimicrob. Agents Chemother. 2018, 62, 1-20. [CrossRef] [PubMed]

46. Nørgaard, S.M.; Jensen, C.S.; Aalestrup, J.; Vandenbroucke-Grauls, C.M.J.E.; de Boer, M.G.J.; Pedersen, A.B. Choice of therapeutic interventions and outcomes for the treatment of infections caused by multidrug-resistant gram-negative pathogens: A systematic review. Antimicrob. Resist. Infect. Control 2019, 8, 170. [CrossRef] [PubMed]

47. Zhang, H.; Seward, C.H.; Wu, Z.; Ye, H.; Feng, Y. Genomic insights into the ESBL and MCR-1-producing ST648 Escherichiacoli with multi-drug resistance. Sci. Bull. 2016, 61, 875-878. [CrossRef] [PubMed]

48. Hernández, M.; Iglesias, M.R.; Rodríguez-Lázaro, D.; Gallardo, A.; Quijada, N.; Miguela-Villoldo, P.; Campos, M.J.; Píriz, S.; López-Orozco, G.; de Frutos, C.; et al. Co-occurrence of colistin-resistance genes mcr-1 and mcr-3 among multidrug-resistant Escherichia coli isolated from cattle, Spain, September 2015. Eurosurveillance 2017, 22, 30586. [CrossRef] [PubMed]

49. Mohsin, M.; Raza, S.; Roschanski, N.; Schaufler, K.; Guenther, S. First description of plasmid-mediated colistin-resistant extendedspectrum $\beta$-lactamase-producing Escherichia coli in a wild migratory bird from Asia. Int. J. Antimicrob. Agents 2016, 48, 463-464. [CrossRef]

50. Tzouvelekis, L.S.; Markogiannakis, A.; Psichogiou, M.; Tassios, P.T.; Daikos, G.L. Carbapenemases in Klebsiella pneumoniae and other Enterobacteriaceae: An evolving crisis of global dimensions. Clin. Microbiol. Rev. 2012, 25, 682-707. [CrossRef] [PubMed]

51. Grundmann, H.; Glasner, C.; Albiger, B.; Aanensen, D.M.; Tomlinson, C.T.; Andrasević, A.T.; Cantón, R.; Carmeli, Y.; Friedrich, A.W.; Giske, C.G.; et al. Occurrence of carbapenemase-producing Klebsiella pneumoniae and Escherichia coli in the European survey of carbapenemase-producing Enterobacteriaceae (EuSCAPE): A prospective, multinational study. Lancet Infect. Dis. 2017, 17, 153-163. [CrossRef]

52. Braun, S.D.; Ahmed, M.F.E.; El-Adawy, H.; Hotzel, H.; Engelmann, I.; Weiß, D.; Monecke, S.; Ehricht, R. Surveillance of ExtendedSpectrum Beta-Lactamase-Producing Escherichia coli in Dairy Cattle Farms in the Nile Delta, Egypt. Front. Microbiol. 2016, 7, 1020. [CrossRef]

53. Stolle, I.; Prenger-Berninghoff, E.; Stamm, I.; Scheufen, S.; Hassdenteufel, E.; Guenther, S.; Bethe, A.; Pfeifer, Y.; Ewers, C. Emergence of OXA-48 carbapenemase-producing Escherichia coli and Klebsiella pneumoniae in dogs. J. Antimicrob. Chemother. 2013, 68, 2802-2808. [CrossRef]

54. Bachiri, T.; Bakour, S.; Lalaoui, R.; Belkebla, N.; Allouache, M.; Rolain, J.M.; Touati, A. Occurrence of Carbapenemase-Producing Enterobacteriaceae Isolates in the Wildlife: First Report of OXA-48 in Wild Boars in Algeria. Microb. Drug Resist. 2018, 24, 337-345. [CrossRef]

55. Vittecoq, M.; Godreuil, S.; Prugnolle, F.; Durand, P.; Brazier, L.; Renaud, N.; Arnal, A.; Aberkane, S.; Jean-Pierre, H.; Gauthier-Clerc, M.; et al. Antimicrobial resistance in wildlife. J. Appl. Ecol. 2016, 53, 519-529. [CrossRef]

56. Karkman, A.; Do, T.T.; Walsh, F.; Virta, M.P.J. Antibiotic-Resistance Genes in Waste Water. Trends Microbiol. 2018, 26, 220-228. [CrossRef]

57. Han, B.; Yang, F.; Tian, X.; Mu, M.; Zhang, K. Tracking antibiotic resistance gene transfer at all seasons from swine waste to receiving environments. Ecotoxicol. Environ. Saf. 2021, 219, 112335. [CrossRef] [PubMed]

58. Zhou, S.-Y.-D.; Zhu, D.; Giles, M.; Daniell, T.; Neilson, R.; Yang, X.-R. Does reduced usage of antibiotics in livestock production mitigate the spread of antibiotic resistance in soil, earthworm guts, and the phyllosphere? Environ. Int. 2020, 136, 105359. [CrossRef] [PubMed] 